\section{The}

DOI : 10.15740/HAS/TAJAS/12.1/85-87

Visit us | www.researchjournal.co.in "S

A CASE STUDY........

\title{
Panda: Focus and role of biological research for conservation
}

\section{SUKANTA SARKAR}

AUTHOR FOR CORRESPONDING :

\section{SUKANTA SARKAR}

Department of Social Science and

Humanities, Faculty of

Management Studies, ICFAI

University, AGARTALA,

(TRIPURA) INDIA

Email: sukantaeco@gmail.com

\begin{abstract}
Panda are two types: (a) Giant panda and (b) red panda. Giant pandas are black and white bears. The red panda is dwarfed by the black-and-white giant that shares its name. The giant panda is a vulnerable species, threatened by continued habitat loss and habitat fragmentation and by a very low birthrate, both in the wild and in captivity. Habitat loss and fragmentation have reduced its numbers, shrunk its distribution and separated the population into isolated subpopulations. The main objectives of this paper are: (a) to study the situation of panda in Himalayan region and (b) to identify the reasons for reducing numbers of panda.
\end{abstract}

KEY WORDS....... Red panda, Giant panda, Bamboo, Population explosion, Mountain

HOW TO CITE THIS ARTICLE - Sarkar, Sukanta (2017). Panda: Focus and role of biological research for conservation. Asian J. Animal Sci., 12(1): 85-87. DOI : 10.15740/HAS/TAJAS/12.1/85-87.

ARTICLE CHRONICLE - Received : 23.01.2017; Accepted : 28.05.2017 